\title{
The Agreement of Structural Obliques Parameter. Pseudopartitives, DOM and Partitive Articles in Romance
}

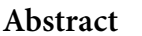

The core proposal of this contribution is that in $[\mathrm{P} \mathrm{DP}]$ or [K DP] structures, where K, $\mathrm{P}$ are oblique prepositions or cases, either $\mathrm{P} / \mathrm{K}$ or $\mathrm{DP}$ can label the resulting constituent. If $\mathrm{PP} / \mathrm{KP}$ is the resulting label, the constituent does not provide a goal for Agree. If DP is the resulting label, the constituent behaves like any other DP, providing a goal for Agree. This is what we call the agreement parameter for structural obliques. Inherent obliques, i.e. those selected by a predicate, obligatorily project as PP/KP. In section 1 we use this hypothesis to explain variation in the agreement pattern of pseudopartitives, in section 2 we institue a parallelism with Differential Object Marking (DOM). In section 3, we illustrate a consequence of the same labelling algorithm independent of agreement, arguing that so-called Romance partitive articles include the partitive preposition $d i$ 'of', but at the same time project as DPs.
\end{abstract}

\section{Keywords $\bigotimes$}

partitive, pseudopartitive, Differential Object Marking, labelling

\section{Pseudopartitives: labelling, constituency, agreement}

Pesetsky (1982), Franks (1994) discuss Russian quantified structures of the type in (1) and their agreement patterns. The quantifier embeds a genitive NP and the verb agrees either with this NP in the plural, or else shows up in the neuter singular form. Pesetsky (1982: 89) suggests a dual labelling analysis, namely that "in a phrase of the form $\left[_{\mathrm{XP}} \mathrm{Q} \mathrm{N}\right], \mathrm{X}$ must be either $\mathrm{Q}$ or N. A noagreement numeral phrase is a QP; an agreement numeral phrase is an NP". In 
other words, "if we assume that a verb agrees with an NP, but not with a QP, we account for the agreement facts."
(1) Neskol'ko studentov pročitali/pročitalo ètu knjigu. several students-GEN read-PL/read-sG this book 'Several students read this book.' Russian (Franks 1994:615)

Quantificational structures of the type in (1) are not confined to Slavic languages; judging from Toosarvandani and Nasser (2017), they are equally pervasive in Persian. English and the Romance languages also partially reproduce the pattern. Thus in English the quantified structure in (2a) obligatorily triggers plural agreement but not the pseudopartitive structure in $(2 \mathrm{~b})$, which alternates between singular and plural agreement with the finite verb.

(2) a. Some senators are voting against the proposal.

b. A group of senators is/are voting against the proposal.

In Italian (3), the presence of a (pseudo)partitive DP in subject position triggers optionality in agreement with the finite verb with respect to both number and gender. Specifically, the verb may agree with una parte 'a part', i.e. the head of the (pseudo)partitive, showing up in the feminine singular (henceforth head agreement). Alternatively it may agree with the embedded genitive/ of NP, showing up in the masculine plural (henceforth embedded agreement).

(3) Una parte di/dei senatori si è astenuta/ sono astenuti. a part-FSG of/of.the senator-MPL self is abstrained-FSG/ are abstrained-MPL 'A part of the senators has/have abstained.'

English has so-called semantic agreement, involving the possibility for singular collective DPs to agree with the predicate in the plural, as in The committee has/have met. However (pseudo)partitive agreement in (1)-(3) is a different phenomenon. To begin with, it is not obvious that it is coextensive with semantic agreement, which is not attested for collective singulars in Spanish (Pérez Jiménez and Demonte 2017: 376) or in Italian. Consider furthermore how semantic agreement applies to gender as opposed to number. As far as we can tell it may be involved in mismatches like those in Italian (4a), where the grammatical gender of the DP is mismatched with its natural gender. Nothing of the sort is involved in alternating gender agreement in pseudopartitives as in (4b); the latter phenomenon is syntactic, not semantic. ${ }^{1}$

${ }^{1}$ Smith (2017) models semantic agreement in number (in English) in terms of Concord and Index features. Danon (2013), Perez-Jimenez and Demonte (2017) account for pseudopartitives in the same terms. Concord features would be relevant for DP-internal agreement, and Index features for sentential agreement. According to Perez-Jimenez and Demonte, in pseudopartitives the head of the construct may bear its own Index features or it may copy them from the embedded NP. This determines two possibilities for verb agreement, either with the head's own 
(4) a. La guida è da sola/solo.

the guide-FSG is by alone-FSG/alone-MSG

'The guide is alone/by himself.'

b. Una bottiglia di vino è andata/andato a male.

a/one bottle-FSG of wine-MSg is gone-FSG/gone-MSG bad

'A/one bottle of wine has gone bad.'

Adopting the classical labelling and constituency line of explanation, we begin by making explicit our assumptions on the internal structure of (pseudo) partitives. We assume that the $d i$ 'of' preposition carries inclusion content in the sense of Belvin and den Dikken (1997), Manzini and Franco (2016). In the structure in (5) for Italian (3), the P elementary relator di 'of' labels its projection as PP. The latter is then read as a complement of the N parte 'part'. Agreement of the verb with the embedded DP is impossible for locality reasons (the PIC, according to Lorusso and Franco 2017). Therefore the head DP determines singular agreement with the verb.

(5) $\left[_{\mathrm{DP}(\varphi)}\right.$ una $\left[_{\mathrm{NP}(\varphi)}\right.$ parte $\left[_{P P}\right.$ di/de $\left[_{\mathrm{DP}}\right.$ (i) senatori $\left.\left.]\right]\right]$ si è $\ldots$

head agreement

We propose that a second labelling option is allowed for (3), along the lines of (6). In (6) as in (5), the adposition di 'of' has an elementary relator content. However, $d i$ is not construed as heading its own projection. Rather, (i) senatori 'the senators' labels the embedded genitive as DP. This means that una parte 'a part' can only be construed as a phrasal modifier, adjoined to the DP projection of (i) senatori. The $\varphi$-features of the DP as a whole are those of (i) senatori and agreement is in the plural.

(6) $\left[_{D \mathrm{DP}(\varphi)}\right.$ [una parte] $\left[_{D P(\varphi)}\right.$ di/de $\left[_{\mathrm{DP}(\varphi)}\right.$ (i) senatori $\left.\left.]\right]\right]$ si sono ... embedded agreement

We assume that the same content carried by of in English or $d i$ in Italian can also be carried by genitive case. We then predict that the two labelling options in (5)-(6) are open in Russian, yielding the alternative structures in (7). If $\mathrm{K}$ projects, then it is read as the complement of a higher $\mathrm{D}-\mathrm{N}$ structure agreeing in the singular, as in (7a); if NP projects then it agrees with the higher $\mathrm{D}$ and determines agreement with the verb in the plural, as in (7b).

(7) a. [ ${ }_{\mathrm{DP}}$ neskol'ko $\mathrm{N} \quad\left[{ }_{K P}\right.$ student $\left.\left.\left[\mathrm{K}_{\mathrm{K}}-\mathrm{ov}\right]\right]\right]$

b. $\left[_{\mathrm{DP}}\right.$ neskol'ko $\left[_{D P}\right.$ student $\left[{ }_{\mathrm{K}}\right.$-ov $\left.\left.\left.]\right]\right]\right]$

pročitalo ...

pročitali ...

Index features or with those of the embedded NP. We limit ourselves to the observation that this approach requires the doubling of agreement feature sets (Index and Concord). Moreover, the overt morphology of the head of the pseudopartitive is determined by the Concord set; therefore, in the pseudopartitive constructions, the Index set is not motivated independently of the phenomenon of embedded agreement that it is meant to model. See the literature quoted for other possible motivation. 
A considerable number of questions are opened by the proposal in (5)-(6) beginning with the labelling agorithm (LA) that we adopt. The structure in (5) is compatible with Chomsky's (2013) proposal that "LA is just minimal search", so that given $\{\mathrm{H}, \mathrm{XP}\}$, LA will select the closest head $\mathrm{H}$. However, the structure in (6) does not comply with Chomsky's LA. Cecchetto and Donati (2015) propose a different LA, namely that "the label of a syntactic object $\{\alpha, \beta\}$ is the feature(s) that act(s) as a probe for the merging operation creating $\{\alpha, \beta\}$ ”. We rely on the latter to derive (5)-(6).

Consider the structure in (8). As before, we assume that the preposition $d i$ is an elementary predicate, endowed with a general relator content (part/ whole), which as such requires the satisfaction of two argument places. We may conceive of argument saturation as an identification of the referential property D of DP with an open variable slot of $d i$, hence $[\mathrm{x}]=\mathrm{D}$ as in (8). $\mathrm{P}$ probes $\mathrm{D}(\mathrm{P})$, in the sense that $\mathrm{P}$ holds the unvalued property set and $\mathrm{D}(\mathrm{P})$ the valued property (set), so that $\mathrm{P}$ labels the constituent as PP.

(8)

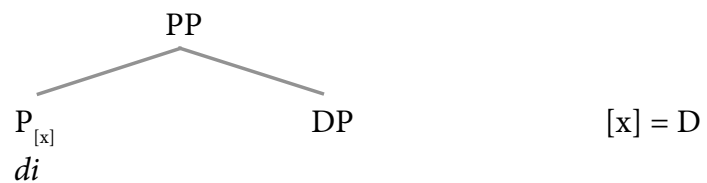

Consider then the structure in (9). The embedded DP in turn requires visibility/case. This may be construed as a $\mathrm{K}$ feature of DP that is valued as genitive when DP saturates the argument place of $d i$ - essentially extending Chomsky's (2001) treatment of direct cases to structural obliques. In this reading, it is the $\mathrm{K}$ feature of $\mathrm{DP}$ that probes for $\mathrm{P}$, in the sense that $\mathrm{P}$ values $\mathrm{K}$ as genitive, leading to the projection of DP.

(9)

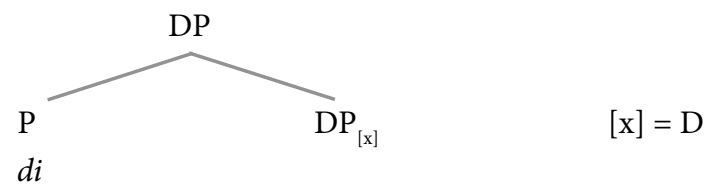

Informally, in (8), DP is a complement embedded in PP, in (9) P is the case/visibility projection on the functional spine of DP. The PP label implies that the embedding head determines sentential agreement in (5); the DP label implies that sentential agreement is determined by the embedded DP in (6). Recall that in the conception of Berwick and Chomsky (2011) parameters are essentially degrees of freedom left open by Universal Grammar. In this sense, the labelling alternation is a parameter. Therefore we expect that a particular value may be chosen (or suppressed) by a given language (in a given context). We will see a parametrized manifestation of the labelling in section 2 .

Evidently, we do not want the LA in (8)-(9) to interfere with established instances of unambiguous projection. As far as we can see, other instances of 
structural case assignment, by $\mathrm{T}$ and $v$, do not involve sisterhood configurations, so that (8) cannot apply. Indeed the $v$ probe has the object of VP has its goal - and the $\mathrm{T}$ probe has the external argument in Spec, $v \mathrm{P}$ as its goal. We defer to section 2 the discussion of how projection of PP along the lines of (8) is forced in instances where PP is selected by a verb, i.e. in instances of inherent obliques (Chomsky 1986), eventually justifying the reference to structural obliques in the agreement parameter of the title.

Another relevant question is whether the structural alternations in (5)-(9) correspond to interpretive differences. One of the clearest mappings between structure/agreement and interpretation concerns examples like (4b) above, where as Landman (2016), Rothstein (2017) point out, a/one bottle of wine may refer either to a bottle containing wine or to the quantity of wine contained in a bottle. In (10) we provide informal meanings adapted from Landman (2016).

(10) a. one bottle of wine $\rightarrow$ one $\cap$ (bottle (wine))

bottle applies to wine; one intersects with the result.

b. one bottle of wine $\rightarrow$ (one $\circ$ bottle $) \cap$ wine one composes with bottle; the result intersects with wine.

The reading in (10a) can be teased apart by means of a suitable predicate, as in (11). Importantly, this has reflexes on agreement, since only head agreement (with bottiglia 'bottle') is possible, while embedded agreement is excluded.

(11) Una bottiglia di vino era posata/ ${ }^{*}$ posato sul tavolo.

a/one bottle of wine was resting-F/ ${ }^{*}$ resting- $\mathrm{M}$ on the table

'A/one bottle of wine was on the table'.

Since embedded agreement corresponds to structure (6), we conclude that structure (6) excludes the reading (10a) and can only receive the measure reading in (10b). This corresponds to the fact that, given the constituent structure in (6) the matrix D/Q must obligatorily compose with bottiglia 'bottle' previous to composition with the embedded DP. Vice versa, the structure in (5) and head agreement are ambiguous between the two readings (essentially Landman's conclusion for both English and Dutch). ${ }^{2}$

\footnotetext{
${ }^{2}$ Pérez-Jiménez and Demonte (2017) propose that embedded agreement correlates with a distributive reading, which would be impossible with head agreement. In (i) knowledge of the singular nature of the PI in a project forces the distributive reading, without any effect on agreement. Tests with floated each should be avoided because of the syntactic, rather than semantic, requirements on it.
}

(i) Una parte di/dei professori è/sono PI in qualche progetto. a part of/of.the professors is/are PI in some project 'A part of (the) professors is/are PI in some project.' 
The discussion so far also helps us understanding why even limiting ourselves to of- $D P$ environments, the double labelling possibility is not open with possessor structures. Rather embedded agreement is impossible, as in (12). The reason is that (12) requires the individual reading of the head il voto 'the vote', which is only compatible with the structure in (5) and hence with head agreement. By contrast the embedded agreement structure in (6) is only compatible with a measure reading of the head, as just discussed in relation to (11).

(12) Il voto dei senatori ha/ ${ }^{\star}$ hanno cambiato la situazione. the vote of the senators has/have changed the situation 'The vote of the senators has/*have changed the situation.'

\section{Agreement of structural obliques: DOM}

In this section, we discuss Differential Object Marking (DOM) as another example of the dual labelling and agreement of structural obliques. Our discussion presupposes recent approaches to DOM, in which DOM objects are not just morphologically syncretic with obliques (specifically datives), but are represented as obliques in the syntax (Torrego 2009; Pineda 2014; Manzini and Franco 2016). ${ }^{3}$

Following Kayne (1984) and much subsequent literature, in ditransitive sentences like John gave a book to Mary, a possession relation holds between the goal Mary and the theme of the ditransitive verb the book. We assume that this possession relation is established by the elementary $a$ 'to' relator which takes Mary as its internal argument and the book as its external argument.

When it comes to DOM, the intuition is that in a Spanish example like (13a), from Torrego (2009), the verb contratar 'hire' can be paraphrased as 'give/make a contract to/with'. In structure (13b), we adopt the standard minimalist assumption that transitive predicates result from the incorporation of an elementary state/event $\mathrm{V}$ into a transitivizing $v$ layer. Within such a framework, in (13b) the two arguments of $a$ are its object DP una amiga 'a friend' and the result event contrato 'contract', where 'a friend' includes/ locates/ possesses the 'contract' result. The sensitivity to the two layered $v$-V structure characterizes only highly ranked referents. By contrast, indefinite/inanimate complements are embedded as accusative themes. ${ }^{4}$

(13) a. Han contratado *(a) una amiga/Julia/mi amiga.

they.have hired (to) a friend/Julia/my friend

'They hired a friend/Julia/my friend.'

b. $\left[_{\mathrm{vP}} v\left[_{\mathrm{VP}}\right.\right.$ contratado $\left[_{\mathrm{PP}}\right.$ a $\left[_{\mathrm{DP}}\right.$ una amiga $\left.\left.\left.]\right]\right]\right]$

\footnotetext{
${ }^{3}$ See Bárányi (2018) for an up to date opposed view and fn. 5 below.

${ }^{4}$ Torrego (2009), Pineda (2014) adopt an Appl structure, whereby both thematic and DOM datives are positioned in Spec, ApplP.
} 
The syncretism of goal dative and of DOM is based on the fact that at least in the range of languages that we are considering here, object DPs which are referentially highly ranked require for their embedding the same elementary relator P introducing goals, as in (14). ${ }^{5}$

(14) DOM (subject to parametric variation)

$\left.\left[{ }_{\mathrm{VP}} \ldots{ }^{*}(\mathrm{P} / \mathrm{K}) \mathrm{DP}\right] \ldots\right]$ where $\mathrm{DP}$ is highly ranked

The relevance of DOM for the agreement of structural obliques can be seen when we turn to Indo-Aryan languages, where the morphological expression of DOM also generally coincides with that of goal datives. In ergative alignments, we observe that absolutive objects agree with the perfect participle, as in Punjabi (15b). However DOM objects do not; a DOM internal argument triggers an invariant (masculine, singular) inflection on the perfect participle, as in (15a). Note that in (15b), the goal dative is embedded under the - $n u$ postposition, like the DOM argument in (15a).

(15) a. me: o-nu/una-nu dekkh-ea

I s/he-DOM/they-Dom see.PERF-MSG

'I saw him/her/them.'

b. o-ne kita:b ditt-i (si) una-nu

s/he-ERG book.FSG give.PERF-FSG be.PAST they-DAT

'S/he gave the book to them.'

Punjabi

In other Indo-Aryan languages, on the other hand, DOM arguments agree with the verb in ergative alignments, exactly like absolutive objects, as in Marwari (Rajasthani) (16). The same naim morpheme externalizing the DOM object in (16a) also attaches to goal dative in (16b).

(16) a. mhaim śaraṇ-naim dekh-ī

I Sharan.F.SG-DOM see-PST.F.SG

'I saw Sharan.'

b. bābū mha-naim baiṭh jāv-ṇai-ro isāro kar-yo

boss I-DAT sit go-INF-GEN sign.M make-PST.M.SG

'The boss made me a sign to sit down.'

Marwari (Verbeke 2013: 230)

Briefly, DOM elements may agree with perfect participles, patterning with other internal arguments, as in Marwari (16) or they may pattern with other

\footnotetext{
${ }^{5}$ Objections to this approach include the possibility of passivizing DOM but not goal datives; this is explicitly discussed by Manzini and Franco (2016: 219-222). The semantic plausibility of associating an oblique structure not only with causative predicates like contratar 'hire' but also with non-causative predicates is also explicitly discussed by Manzini and Franco (2016: 222-225). Other well-known difficulties arise under cliticization and clitic doubling, briefly surveyed by Manzini and Franco (2016: 235-236) and explicitly discussed by Manzini et al. (to appear).
} 
obliques, notably goal datives, in not undergoing perfect participle agreement, as in Punjabi (15). We propose that the agreement parameter in (15)-(16) depends on the same labelling algorithm that we used to account for pseudopartitive agreement in section 1. Suppose that in Punjabi (15a) the -nu postposition introducing the DOM argument una 'they' labels the resulting constituent as a PP. As a consequence the DOM object $u n a-n u$ 'they-Dom' does not undergo Agree, as indicated in (17).

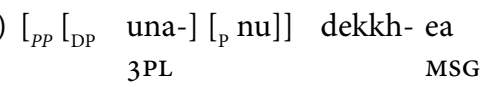

Punjabi

Alternatively, upon Merge of $\mathrm{P}$ and DP, the resulting constituent may be labelled by $\mathrm{D}(\mathrm{P})$, so that it undergoes Agree like any object $\mathrm{DP}$. We propose that this is what happens to the DOM object in Marwari (16a) with the structure in (18); since śaran 'Sharan' is feminine singular, so is the perfect participle inflection $-i$.

$$
\left[_ { D P } \left[\begin{array}{ll}
\text { DP śaran- }-] \\
\text { FSG }
\end{array}\right.\right.
$$

Marwari

One important property of the labelling parameter is that it does not affect dative goals though they are otherwise indistinguishable from DOM objects. In other words, even in Marwari "agreement with an IO or an experiencer, marked with the same postposition, is out of the question" (Verbeke 2013:234). In present terms, this means that only the structure in (19), where PP projects, is possible for goal datives, so that they cannot be goals for agreement probes.

(19) $\left[_{P P}\left[{ }_{D P}\right.\right.$ mha- $]\left[{ }_{P}\right.$ naim $\left.]\right]$

Marwari

Our explanation for the contrast between the Marwari DOM oblique in (18) and the goal oblique in (19) relies on the assumption that the DOM oblique in (18) is structural, i.e. it depends on the configuration in (15) being realized while the goal oblique in (19) is inherent, i.e. it is selected by the verb 'make a sign/signal. Labelling by $\mathrm{D}(\mathrm{P})$ as opposed to labelling by $\mathrm{P}$ is impossible with inherent obliques, because they need to project the $\mathrm{P}$ content as part of the fact that their $\mathrm{P}$ properties are selected by the verb. Hence the agreement parameter only affects structural obliques such as DOM and not the same obliques when they are inherent. ${ }^{6}$

\footnotetext{
${ }^{6}$ In present terms the Visibility of Inherent-Case to Verbal Agreement (VIVA) Parameter of Anand and Nevins (2005) is replaced by the visibility of structural obliques to verbal agreement. Instances of variation in agreement meant to fall under the VIVA, are in principle encompassed by our proposal. Specifically, ergative subjects do not undergo agreement with the verb in many Indo-Aryan languages (e.g. Punjabi) but nevertheless display agreement in others, for instance Nepali. See Manzini and Franco (2019) for some discussion, implying that ergative is a structural oblique.
} 
Manzini and Franco (2016: 2019-222) use the same structural/inherent opposition to derive the impossibility for goal datives to passivize, i.e. undergo raising to the nominative (Spec, TP) position. For, they are selected as PPs and must appear as such in the structure. Any passivization that preserves the PP is wellformed, such as P-stranding in English (John was given a book to) or impersonal passive in other languages. By contrast, any internal argument can undergo passivization, independently of what case (DOM or other) it would receive in the VP.

The same agreement parameter seen in macrovariation in Indo-Aryan languages can also be seen in microvariation in the double agreement pattern of certain object clitics in Romance. In Italian, accusative 3P clitics obligatorily agree with the perfect participle, as originally discussed by Kayne (1989). Interestingly, $1 / 2 \mathrm{P}$ object clitics can either agree with the perfect participle, or not agree with it, as illustrated in (20).

(20) $\mathrm{Mi} / \mathrm{ti}$ hanno chiamata/chiamato.
me.F/you.F they.have called-F/called-m
'They called me(f.)/you(f.).'

Following Manzini and Savoia (2014), there is considerable evidence that $1 / 2 \mathrm{P}$ pronouns undergo DOM in Romance. In present terms this means that they are obliques. Indeed they can be analyzed as consisting of a lexical base [D $\mathrm{m}-/ \mathrm{t}$-] and of an oblique $\mathrm{K}$ inflection [K-i]. This is consistent with morphological evidence, since in traditional terms, accusative and dative are syncretic in the $1 / 2 \mathrm{P}$; in other words, $m i / t i$ are also the indirect object clitics, as in (21). ${ }^{7}$
(21) $\mathrm{Mi} / \mathrm{ti}$ hanno dato un libro.
to.me/you they.have given a book
'They gave me/you a book.'

Based on the discussion of Indo-Aryan (21)-(22), we may model the agreement alternation in (20) as in (22). In other words, the $1 / 2 \mathrm{P}$ clitic may be labelled by its $\mathrm{D}$ subconstituent, yielding (22b) and agreement with the perfect participle. Alternatively, it may be labelled by its oblique K subconstituent yielding (22a) and no agreement.

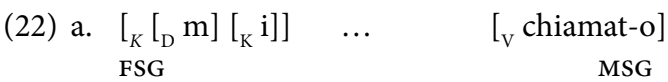

$$
\begin{aligned}
& \text { b. } \underset{\text { FSG }}{\left[_{D}\left[{ }_{\mathrm{D}} \mathrm{m}\right]\right.}\left[\left[_{\mathrm{K}} \mathrm{i}\right]\right] \quad \cdots \quad \underset{\text { FSG }}{\left[{ }_{\mathrm{V}} \text { chiamat-a }\right]}
\end{aligned}
$$

${ }^{7}$ We take the status of $m$-/t- as bearers of $1 / 2 \mathrm{P}$ content to be uncontroversial; as for the oblique analysis of $-i$, see Manzini and Savoia (2014). An independent argument in favour of the oblique status of $1 / 2 \mathrm{P}$ is their position in the clitic string, different from that of accusative $3 \mathrm{P}$ and overlapping with that of dative 3P anf of the locative/instrumental clitic (Manzini and Savoia 2017). 


\section{Partitive articles}

In this section we consider the question, whether dual labelling can be detected independently of interactions with Agree. We argue that this is so, specifically with of/genitive phrases. In Italian or French, de/di phrases can correspond to selected arguments of a verb, hence to inherent genitives. In these instance the projection of $\mathrm{PP}$ is forced by the fact that $\mathrm{P}(\mathrm{P})$ is selected for, as indicated in structure (23b) for example (23a).

(23) a. Gianni si spaventa subito dei problemi. John self fears immediately of.the problems 'John immediately starts fearing problems.'

b. ${ }_{P P}$ de $\left[{ }_{D P}\right.$ i problemi $\left.]\right]$

Phrases identical to PP constituents such as dei problemi 'of the problems' in (23) occur however also in subject and direct object position where they are in complementary distribution with DPs. The DP status of the postverbal subject dei problemi 'problems' in (24) is confirmed by agreement with the verb. The interpretation is akin to that of English bare plurals, hence existential in (24); the same phenomenon is attested in French (Dobrovie-Sorin and Beyssade 2012).

(24) Sono sorti dei problemi/arrivati dei ragazzi. are arisen of.the problems/arrived of.the boys 'Problems have come up/Boys have arrived.'

Based on the discussion in section 1, we propose that the structure for the $d i$ phrase (24) is as in (25). On the one hand, $d i$ 'of' is the same preposition as in (23); on the other hand, the constituent embedding it is labelled not by $\mathrm{P}$ but by $\mathrm{D}$, as $\mathrm{DP}$.

(25) $\left[_{D P}\left[{ }_{P}\right.\right.$ de $]\left[{ }_{D P}\right.$ i problemi/ragazzi $\left.]\right]$

The important point for present purposes is that if this line of analysis is correct, we have yet another argument in favour of our labelling parameter. Nevertheless even if (25) satisfies all syntactic desiderata, the question arises whether it returns the correct interpretation. If $d i$ is the same element in (25) as in (23), it carries an elementary relator content, which we roughly identify with part/ whole. The internal argument of the relator $\mathrm{P}$ is the embedded DP $i$ problemi/ ragazzi 'the problems/boys'. Given the lack of a syntactic representation for the external argument of the relator $\mathrm{P}$, we would have to assume that the latter remains an open variable in the argument structure of $P$. The variable is closed existentially at the interpretive interface, yielding an LF along the lines of (26).

(26) $\exists \mathrm{x}, \mathrm{x}\left[_{D P}\left[{ }_{\mathrm{P}} \mathrm{de}\right]\left[_{\mathrm{DP}}\right.\right.$ i problemi/ragazzi $\left.]\right]$ 
The LF in (26) is essentially the same proposed by Chierchia (1998). Syntactically, for Chierchia (1998), the di phrase is embedded into an empty $\mathrm{N}$ associated with the property [part]. In the course of the derivation, the embedded $\mathrm{D}$ incorporates into $d i$, which is semantically empty for Chierchia, and "finally the result incorporates into the higher D position," along the lines of (27). From an interpretive point of view "incorporation of the article first into $\mathrm{P}$ and then into $\mathrm{N}$ amounts, semantically, to the composition of the 'part-of' relation with the article's meaning," namely $\subseteq{ }^{\circ}$ I. "The next step is movement of the N-P-D complex into the higher D. This must involve type shifting, ... so one must resort to $\exists$ ", in other words $\exists^{\circ} \subseteq{ }^{\circ} \mathrm{t}$.

(27) $\left[_{D P}\right.$ dei $\left[_{N P}\right.$ dei $\left[{ }_{\mathrm{PP}}\right.$ dei $\left[{ }_{\mathrm{DP}}\right.$ i ragazzi $\left.\left.\left.]\right]\right]\right]$

(Chierchia 1998: 90)

In our structure (25), as opposed to Chierchia's (27), there is no head movement (argued against by Chomsky [2001]). This is because we do not need head movement to have a P immediately dominated by a DP - the labelling algorithm does this for us. There is also no silent N. This is because the part/ whole content is carried by the preposition di. All in all, there seem to be no more assumptions than in Chierchia, and certainly fewer derivational steps, leading nevertheless to the same interpretive result.

Chierchia's (1998) semantics has been argued to be inadequate, in that it treats dei ragazzi like alcuni dei ragazzi 'some of the boys', incorrectly (Storto 2003). In subsequent work, Zamparelli (2008) suggests that the article $i$ in dei ragazzi does not denote $\mathrm{\iota}$ but rather is expletive (in the sense of Longobardi 1994). Therefore the embedded DP $i$ ragazzi is kind-denoting. Furthermore, for Zamparelli, the preposition di embodies an operator R ('residue') which returns the denotation of its specifier minus the denotation of its complement.

Consider then Zamparelli's structure in (28). The complement of $d i$ is $i$ rag$a z z i$. The specifier is filled by a copy of ragazzi in keeping with general assumptions about partitives - where ragazzi "denotes a plural property." Since the [boy]-kind denoted by the embedded DP is not a member of the set of pluralities of [boys], denoted by the higher NP, "the residue operation applies vacuously." This means that it returns "the plural property 'boys' as the denotation of the whole expression" (Zamparelli 2008: 320).

(28) $\left[_{\mathrm{PP}}\left[{ }_{\mathrm{NP}}\right.\right.$ agazzi] $\left[_{\mathrm{P}^{\prime}}\right.$ de $\left[_{\mathrm{DP}} \mathrm{i}\right.$ ragazzi $\left.\left.]\right]\right]$

(Zamparelli 2008: 323)

Can the present syntax map to something like Zamparelli's semantics? We would need to assume that instead of representing the external argument of $d i$ as a variable, it is represented as a copy of the embedded NP ragazzi, along the lines of (29), thus recreating the exact configuration of Zamparelli. At the same time, given (28) Zamparelli still needs to assume that the PP is selected by some higher D-Num functional structure to which dei is raised, after incorporation of the article into the preposition, along the lines of Chierchia (1998). The labelling in (29) makes any subsequent syntactic derivation redundant. 


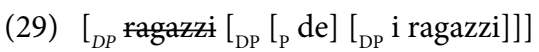

In short, our proposal avoids certain complexities in Chierchia's (1998), and Zamparelli's (2008) syntactic analyses, namely abstract heads and head movement. As for the semantic representations which are the real point of the discussion of Chierchia and Zamparelli, we conclude that they do not specifically require head-raising but are equally compatible with the present labelling implementation, since the head-raising is semantically vacuous in ther account as well.

Cardinaletti and Giusti (2016) also reject the raising analysis of dei. However they differ from the present proposal in that they construe dei as an exponent of the category $\mathrm{D}$. They propose that $d e$ - is a specifier of $\mathrm{D}$ whose inflection $-i$ is realized on D. The two are then fused. In other words the underlying structure of dei ragazzi is as in (36).

(30) $\left[_{\mathrm{DP}}\right.$ de $\left[{ }_{\mathrm{D}^{\prime}}, \mathrm{i}\left[_{\mathrm{NP}}\right.\right.$ ragazzi $\left.\left.]\right]\right]$

(Cardinaletti and Giusti 2016: 64)

According to Cardinaletti and Giusti (2016: 65) de is ambiguous between two categorizations, namely "the determiner (in Spec DP)" and the preposition $\mathrm{P}$. They connect this ambiguity to grammaticalization, specifically to theories of grammaticalization claiming that "language change is structural reanalysis", hence recategorization (cf. Roberts and Roussou 2003). Now, in grammaticalization, morphophonological and semantic change should normally go hand in hand. However, morphophonological evidence is far from robust.

Cardinaletti and Giusti argue that in Anconetano, the realisation of $i$ is optional when $i$ is the inflection of the partitive $\mathrm{D} d e$ in (31a), though it is obligatory when it is the sole exponent of $\mathrm{D}$ (embedded under the preposition $d e$ ) in (31b). ${ }^{8}$ However, the contrast is difficult to reproduce even in other varieties of Italian, for instance the regional Italian of Tuscany/Florence, where $i$ deletion is optional in the possession context in (32), cf. (31b).

(31) a. T’ hai da lege dei/de libri pe sapé la storia. you must to read DE.the/DE books to learn the history 'You must read books to learn history'

b. La cupertina dei/*de libri de storia è sempre un po' sbregata. the cover of.the/of books of history is always a bit broken 'The cover of history books is always a bit broken.'

Ancona (Cardinaletti and Giusti 2016: 65)

(32) la macchina de(i) ragazzi

the car of(the) boys

'the boys' car'

Florence

\footnotetext{
${ }^{8}$ In present terms, we would have to describe Anconetano by differentiating contexts where $i$ projects DP and it can delete (31a) - and contexts where it does not project and it is obligatorily realized (31b).
} 
Even leaving aside doubts as to the explanatory value of grammaticalization, it seems that the empirical evidence for morphophonological reduction is at present quite limited. More importantly, we achieve the result of having partitive articles project a DP constituent, which is the basic desideratum of Cardinaletti and Giusti, without having recourse to grammaticalization.

Concluding this section, we have argued that the labelling parameter originally devised in section 1 to account for agreement/non-agreement alternations with structural obliques turns out to be useful in accounting for the partitive articles of Romance. On the one hand, we require no recourse to grammaticalization leading from a $\mathrm{P}$ to a $\mathrm{D}$ categorization for $d i$ 'of'. On the other hand, the categorial label DP for the bare partitive is obtained without having recourse to head-to-head movement/incorporation. The present account is motivated by syntactic considerations. However in the discussion that precedes we have indicated how the syntax we propose may be (made) compatible with Chierchia's (1998) or Zamparelli's (2008) semantics.

\subsection{The ne clitic}

In the final brief case study of this contribution, we go back to section 2, namely to Romance clitics and to the agreement parameter. Belletti and Rizzi (1996) study optional agreement of the Romance partitive clitic with the perfect participle. In Italian (33a) many speakers allow both agreement in the plural and lack thereof. Similarly agreement in the feminine singular may take place or not as in (33b). Recall that agreement must be determined by the clitic, because Romance perfect participles do not agree with objects in situ, but only with objects moved to their left (Kayne 1989).
(33) a. $\mathrm{Ne}$

$\begin{array}{llll}\mathrm{Ne} & \text { ha ridipinte/ } & \text { ridipinto } & \text { due. } \\ \text { of.them has repainted-FPL/ } & \text { repainted-sG } & \text { two } \\ \text { 'He has repainted two of them.' } & \end{array}$
b. Ne ho vist-a /vist-o solo una.
PART I.have seen-FSG/seen-MSG only one-FSG
'I saw only one (f.).'

Italian

Belletti and Rizzi propose that the structure of a partitive phrase containing ne is as in (31), where ne corresponds to an oblique KP. The crucial difference between agreeing and non agreeing grammars consists in whether $\phi$-features are or are not associated with the KP node. KP moves out of QP via the Spec, QP position, triggering agreement with $\mathrm{Q}$ if $\mathrm{KP}$ is endowed with $\phi$-features, as in (34a). In turn if KP is endowed with $\phi$-features agreement with the perfect participle ensues. Otherwise movement of $n e$ takes place as before but no agreement with either $\mathrm{Q}$ or the perfect participle ensues, as in (34b). 
(34) a. $\left[_{Q P}\right.$

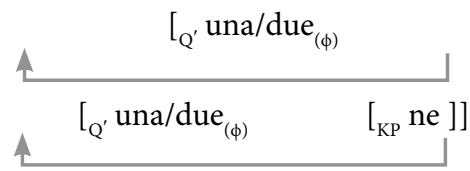

$\left.\left[\mathrm{KP} n \mathrm{e}_{(\phi)}\right]\right]$

b. $\left[_{Q P}\right.$

KP ne ]]

(Belletti and Rizzi 1996)

The labelling parameter introduced in section 1 allows us to model Belletti and Rizzi's proposal in such a way as to unify it it with the various other phenomena considered in this article. We assume that the $n e$ clitic consists of a lexical base $n$ - carrying the relational content partitive/genitive, hence categorized as $\mathrm{K}$; $\mathrm{K}$ selects a nominal inflection $-e$, which we may simply categorize as $\mathrm{N}$, endowed with all the properties of $\mathrm{N}$, including $\phi$-features. ${ }^{9} \mathrm{On}$ this basis, we predict that $n e$ as a whole may be labelled by $\mathrm{N}-$ or it may be labelled by oblique K properties.

Suppose first that $\mathrm{N}$ projects, as in (35); then the $\mathrm{N}$ constituent agrees with the Q constituent, by routine DP-internal Agree/Concord. As the ne clitic moves to $v \mathrm{P}$, it triggers perfect participle agreement, specifically with the features of Q. One bonus of this account is that it is in fact immaterial by which route $n e$ reaches $\mathrm{vP}$ - it could be base generated there binding an empty $\mathrm{N}$-pro embedded under Q (Sportiche 1996).

$$
\ldots\left[\left[_{Q P(\phi)} \text { una/due }\left[_{N(\phi)}\left[{ }_{P} n\right]\left[_{N} e\right]\right]\right]\right.
$$

Alternatively, if $\mathrm{K}$ projects as in (36), agreement of the clitic with the embedding $\mathrm{Q}$ does not take place nor does agreement with the perfect participle.

(36) $\ldots\left[_{\mathrm{QP}(\phi)}\right.$ una/due $\left.\left[{ }_{K}\left[{ }_{\mathrm{K}} \mathrm{n}\right]\left[_{\mathrm{N}} \mathrm{e}\right]\right]\right]$

The account in (35)-(35) is not a notational variant of Belletti and Rizzi's (1996) to the extent that the stipulation that ne may or may not carry $\phi$-features is substituted by a labelling algorithm which, if we are correct, applies to all structural obliques. In this sense, an independently motivated set of assumptions substitutes for an otherwise item-specific parameter.

\section{Conclusions}

Our core proposal is that in $\mathrm{P} / \mathrm{K}-\mathrm{DP}$ structures, either $\mathrm{P} / \mathrm{K}$ or $\mathrm{D}$ can label the resulting constituent. If $\mathrm{PP} / \mathrm{KP}$ is the resulting label, then the constituent behaves like any oblique and notably does not provide a goal for Agree. If DP results, then the constituent behaves like any other DP/NP, providing a goal for Agree. We applied this labelling algorithm to pseudopartitives in section 1 and

\footnotetext{
${ }^{9}$ That $n$-is the partitive content of the clitic is confimed by the fact that (e)n, without nominal inflection, is the partitive clitic in Northern Italian dialects and French. In turn $-e$ is one of the nominal inflections attested on Ns in Italian (incidentally compatible with all genders and numbers, depending on inflectional class).
} 
to DOM objects in section 2. We used the same account for $1 / 2 \mathrm{P}$ Romance clitics in section 2 and for partitive clitics in section 3.1. The labelling analysis also has consequences independent of agreement. Specifically, in section 3 we argued that so-called partitive articles in Romance are formed with the partitive preposition $d i$ 'of', but at the same time project as DPs. In syntax, this allows us to avoid having recourse to head raising of P-to-D or to grammaticalization of $\mathrm{P}$ to $\mathrm{D}$, as required by alternative accounts.

\section{References}

Anand Pranav, Nevins Andrew (2005). The locus of ergative case assignment: Evidence from scope. In Ergativity: Emerging Issues, Alana Johns, Diane Massam, and Juvénal Ndayiragije (eds.), 143-171. Dordrecht: Kluwer Academic Publishers.

Bárány András (2018). DOM and dative case. Glossa 3(1), 97.

Belletti Adriana, Rizzi Luigi (1996). Su alcuni casi di accordo del participio passato in francese $\mathrm{e}$ in italiano [On some cases of past participle agreement in French and in Italian]. In Italiano e dialetti nel tempo: saggi di grammatica per Giulio C. Lepschy [Italian and dialects in time: Essays on grammar offered to Giulo C. Lepschy], Paola Benincà, Guglielmo Cinque, Tullio De Mauro, and Nigel Vincent (eds.), 7-22. Rome: Bulzoni.

Belvin Robert, den Dikken Marcel (1997). There, happens, to, be, have. Lingua 101, 151-183.

Berwick Robert, Chomsky Noam (2011). The biolinguistic program: The current state of its evolution and development. In The Biolinguistic Enterprise, Anne-Marie Di Sciullo and Cedric Boeckx (eds.), 19-41. Oxford: Oxford University Press.

Cardinaletti Anna, Giusti Giuliana (2016). The syntax of the Italian indefinite determiner dei. Lingua 181, 58-80.

Cecchetto Carlo, Donati Caterina (2015). (Re)labeling. Cambridge, Mass: The MIT Press.

Chierchia Gennaro (1998). Partitives, reference to kinds and semantic variation. In Proceedings of Semantics and Linguistic Theory Volume VII, A. Lawson (ed.), 73-98. Cornell University: CLC Publications.

Chomsky Noam (1986). Knowledge of Language. New York: Praeger.

Chomsky Noam (2001). Derivation by phase. In Ken Hale: A Life in Language, Michael Kenstowicz (ed.), 1-52. Cambridge, Mass: The MIT Press.

Chomsky Noam (2013). Problems of projection. Lingua 130, 33-49.

Danon Gabi (2013). Agreement alternations with quantified nominals in Modern Hebrew. Journal of Linguistics 49, 55-92.

Dobrovie-Sorin Carmen, Beyssade Claire (2012). Redefining Indefinites. Dordrecht: Springer

Franks Steven (1994). Parametric properties of numeral phrases in Slavic. Natural Language and Linguistic Theory 12, 597-674.

Kayne Richard (1984). Connectedness and Binary Branching. Dordrecht: Foris.

Kayne Richard (1989). Facets of Romance past participle agreement. In Dialect Variation in the Theory of Grammar, Paola Benincà (ed.), 85-104. Dordrecht: Foris 
Landman Fred (2016). Iceberg semantics for count nouns and mass nouns: Classifiers, measures and portions. The Baltic International Yearbook of Cognition, Logic and Communication 11, 1-48.

Longobardi Giuseppe (1994). Proper names and the theory of N-movement in syntax and logical form. Linguistic Inquiry 25, 609-665.

Lorusso Paolo, Franco Ludovico (2017). Patterns of syntactic agreement with embedded NPs, Lingua 195, 39-56.

Manzini M. Rita, Franco Ludovico (2016). Goal and DOM datives. Natural Language and Linguistic Theory 34, 197-240.

Manzini M. Rita, Franco Ludovico (2019). 'Agreement of structural obliques' parameter: DOM and pseudopartitives. In Differential Objects and Datives - a Homogeneous Class?, Monica Irimia and Anna Pineda (eds.), Special issue of Linguisticae Investigationes 42(1), 83-102.

Manzini M. Rita, Savoia Leonardo (2014). From Latin to Romance: Case loss and preservation in pronominal systems. Probus 26, 217-248.

Manzini M. Rita, Savoia Leonardo (2017). Enclisis/proclisis alternations in Romance: Allomorphies and (re)ordering. Transactions of the Philological Society 115: 98-136

Manzini M. Rita, Savoia Leonardo, Franco Ludovico (to appear). DOM and dative in (Italo)-Romance. In Case, Agreement, and their Interactions: New Perspectives on Differential Object Marking, András Bárány and Laura Kalin (eds.), Berlin: Mouton de Gruyter.

Pérez-Jiménez Isabel, Demonte Violeta (2017). Agreement and interpretation of partitive constructions in Spanish: The dual nature of nominal features. Probus 29(2), 355-395.

Pesetsky David (1982). Paths and Categories. Cambridge, MA: Massachusetts Institute of Technology. PhD dissertation.

Pineda Anna (2014). (In)transitivity borders. A study of applicatives in Romance languages and Basque. Barcelona: Universidad Autonoma de Barcelona. PhD dissertation.

Roberts Ian, Roussou Anna (2003). Syntactic Change: A Minimalist Approach to Grammaticalization. Cambridge: Cambridge University Press.

Rothstein Susan (2017). Semantics for Counting and Measuring. Cambridge: Cambridge University Press.

Smith Peter (2017). The syntax of semantic agreement in English. Journal of Linguistics 53(4), 823-863.

Sportiche Dominique (1996). Clitic constructions. In Phrase Structure and the Lexicon, Johan Rooryck and Laurie Zaring (eds.), 213-276. Dordrecht: Kluwer.

Storto Gianluca (2003). On the status of the partitive determiner in Italian. In Romance Languages and Linguistic Theory 2001, Josep Quer, Jan Schroten, Mauro Scorretti, Petra Sleeman and Els Verheugd (eds.), 315-330. Amsterdam: John Benjamins.

Toosarvandani Maziar, Nasser Hayedeh (2017). Quantification in Persian. In Handbook of Quantifiers in Natural Language: Volume II, Denis Paperno and Edward Keenan (eds.), 665-696. Cham, Switzerland: Springer.

Torrego Esther (2009). Variability in the case patterns of causative formation in Romance and its implications. Linguistic Inquiry 41, 445-470.

Verbeke Saartje (2013). Alignment and Ergativity in New Indo-Aryan Languages. Berlin: De Gruyter. 
Zamparelli Roberto (2008). Dei ex-machina: A note on plural/mass indefinite determiners. Studia Linguistica 63(3), 301-327.

\author{
M. Rita Manzini \\ Dipartimento di Lettere e Filosofia \\ Università di Firenze \\ via della Pergola 60 \\ 50121 Firenze \\ Italy \\ rmanzini(at)unifi.it \\ ORCID: 0000-0002-5288-4210
}


